\title{
Palliation of Obstructive Jaundice: Endoscopic Ultrasound-guided Choledochoduodenostomy in the Presence of Bleeding Duodenal Infiltration Due to Metastatic Urinary Bladder Cancer
}

\author{
Surinder Singh Rana, Ravi Sharma, Rajesh Guptal, Sobur Uddin Ahmed
}

Departments of

Gastroenterology and

${ }^{1}$ Surgery, Postgraduate

Institute of Medical

Education and Research,

Chandigarh, India

\begin{abstract}
- Obstructive jaundice is a common manifestation of malignancies involving pancreaticobiliary area of the gastrointestinal tract. The palliation of obstructive jaundice involves bypassing the obstruction by an endoprosthesis using either endoscopic retrograde cholangiopancreatography (ERCP) or percutaneous transhepatic biliary drainage route. Endoscopic ultrasound-guided choledochoduodenostomy (ECD) is a challenging alternative for obstructive jaundice due to distal bile duct obstruction in patients who have failed ERCP. In this report, we describe a challenging case of disseminated urinary bladder cancer that presented with extensive duodenal as well as periduodenal infiltration leading on to gastrointestinal bleed and severe pruritus along with obstructive jaundice and was successfully managed with initial argon plasma coagulation of bleeding duodenal lesions followed by ECD.
\end{abstract}

KeYwords: Cancer, endoscopic retrograde cholangiopancreatography, endosonography, stent

\section{INTRODUCTION}

$\mathcal{E}$ xtrahepatic biliary obstruction is one of the common manifestations of malignancies involving pancreatic biliary area of gastrointestinal tract, and it usually requires palliation. The obstruction can be bypassed either by placing an endoprosthesis through the papilla using endoscopic retrograde cholangiopancreatography (ERCP) or percutaneously using image-guided transhepatic route. ERCP is successful in more than $90 \%$ of patients who have normal upper gastrointestinal tract anatomy with no luminal obstruction. However, in cases where ERCP is not possible due to various factors such as failed cannulation, obstructed/altered upper gastrointestinal tract anatomy, distorted ampulla, and large periampullary diverticulum, endoscopic ultrasound-guided biliary drainage (EUS-BD) is being increasingly performed as an alternative to percutaneous transhepatic BD (PTBD). ${ }^{[1-7]}$

There are three ways of performing EUS-BD: (i) rendezvous technique, in which guidewire is passed through the papilla through a punctured intrahepatic or extrahepatic bile duct and retrieved by

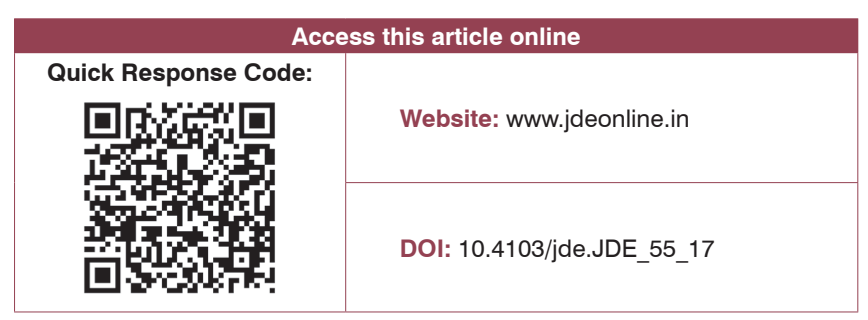

duodenoscope for completion of the procedure through the transpapillary route. (ii) Direct transmural stenting using transgastric hepaticogastrostomy or transduodenal choledochoduodenostomy [ECD] without accessing the papilla. (iii) Antegrade transpapillary stent placement following intrahepatic bile duct puncture. ${ }^{[1-7]}$ The advantage of EUS-BD over percutaneous $\mathrm{BD}$ is that it maintains internal BD. However, in contrast to ERCP and PTBD, it is associated with high complication rates of up to $26 \%$ with bile leak being an important complication. ${ }^{[7]}$ Furthermore, in the presence of extensively infiltrated duodenal mucosa, its safety is not well established.

Here, we describe a challenging case of disseminated urinary bladder cancer that presented with extensive duodenal as well as periduodenal infiltration leading on

Address for correspondence: Dr. Surinder Singh Rana, Department of Gastroenterology, Postgraduate Institute of Medical Education and Research, Sector 12, Chandigarh - 160 012, India. E-mail: drsurinderrana@yahoo.co.in

This is an open access journal, and articles are distributed under the terms of the Creative Commons Attribution-NonCommercial-ShareAlike 4.0 License, which allows others to remix, tweak, and build upon the work non-commercially, as long as appropriate credit is given and the new creations are licensed under the identical terms.

For reprints contact: reprints@medknow.com

How to cite this article: Rana SS, Sharma R, Gupta R, Ahmed SU. Palliation of obstructive jaundice: Endoscopic ultrasound-guided choledochoduodenostomy in the presence of bleeding duodenal infiltration due to metastatic urinary bladder cancer. J Dig Endosc 2018;9:118-21. 
to gastrointestinal bleed and severe pruritus along with obstructive jaundice and was successfully managed with initial argon plasma coagulation (APC) of bleeding duodenal lesions followed by ECD.

\section{Case Report}

A 58-year-old male, known case of transitional cell carcinoma of urinary bladder, presented elsewhere with jaundice, pruritus, and melena. The patient was diagnosed as transitional cell carcinoma of urinary bladder 32 months ago when he was evaluated for hematuria. The patient underwent radical cystectomy and was apparently asymptomatic till 4 weeks ago when he developed gradually progressive obstructive jaundice associated with severe pruritus that was refractory to medical therapy. It was followed by melena 2 weeks later and gradually jaundice also deepened. Investigations revealed anemia (hemoglobin of $5.2 \mathrm{~g} / \mathrm{dl}$ ) and conjugated hyperbilirubinemia (total of $18 \mathrm{mg} \%$ with conjugated being $12.6 \mathrm{mg} \%$ ). Upper gastrointestinal endoscopy revealed narrowing at junction of first and second part of duodenum with extensive infiltration and oozing of fresh blood from the site of narrowing. The gastroscope could not be negotiated beyond the narrowing. Contrast-enhanced computed tomography revealed dilated biliary radicals and common bile duct (CBD) with large lymph nodal mass obstructing the lower part of bile duct [Figure 1a and b]. Ultrasound-guided fine-needle aspiration from the lymph nodal mass revealed it to be metastasis from bladder cancer. Patient was given multiple blood transfusions and referred to our center.

A repeat gastroscopy was performed, and it revealed infiltrated mucosa in both first of duodenum as well as narrowed junction of first and second part of duodenum from where fresh blood was oozing. APC of the bleeding duodenal lesions was done. Following this, the bleeding stopped and the patient was subsequently taken up for ECD after taking informed consent. EUS was done using a linear echoendoscope (GF-UCT 180, Olympus Medical Systems Co., Tokyo, Japan) along with carbon dioxide insufflation and it revealed a dilated CBD that was obstructed at the lower end with a large lymph nodal mass [Figure 2]. The duodenal wall at the site of narrowing was also thickened with loss of wall stratification [Figure 2]. The CBD was punctured from the first part of duodenum, avoiding the infiltrated, thickened duodenal wall using a 19G Flexible EUS needle (Expect, Boston Scientific, Natick, Massachusetts) [Figure $3 \mathrm{a}$ and $\mathrm{b}$ ]. The cholangiogram revealed a dilated CBD with cutoff at the lower end [Figure 4]. Thereafter, a guidewire (VisiGlide; 0.025 inch; straight tip; Olympus Medical Systems Co.,

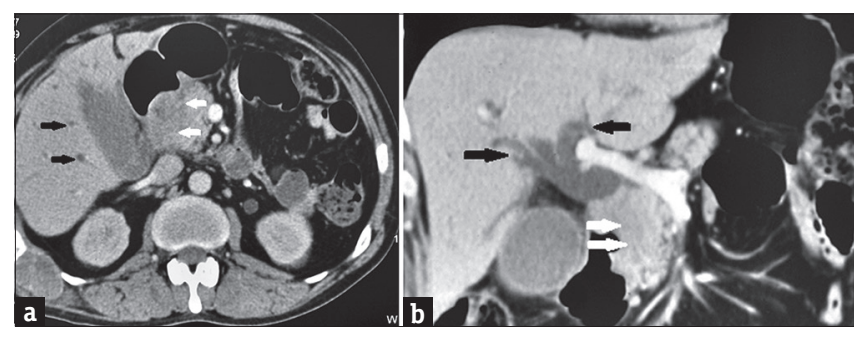

Figure 1: ( $\mathrm{a}$ and $\mathrm{b}$ ) Contrast-enhanced computed tomography: Dilated biliary radicals and common bile duct (black arrow) with large lymph nodal mass (white arrow) obstructing the lower part of bile duct

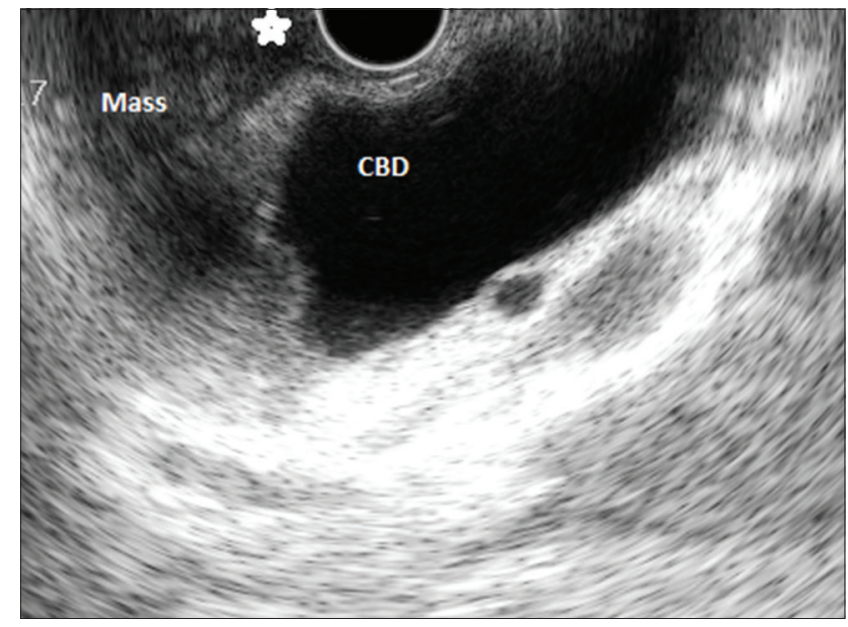

Figure 2: Endoscopic ultrasound: dilated common bile duct with mass obstructing it. Thickened duodenal wall also noted $\left(^{*}\right)$

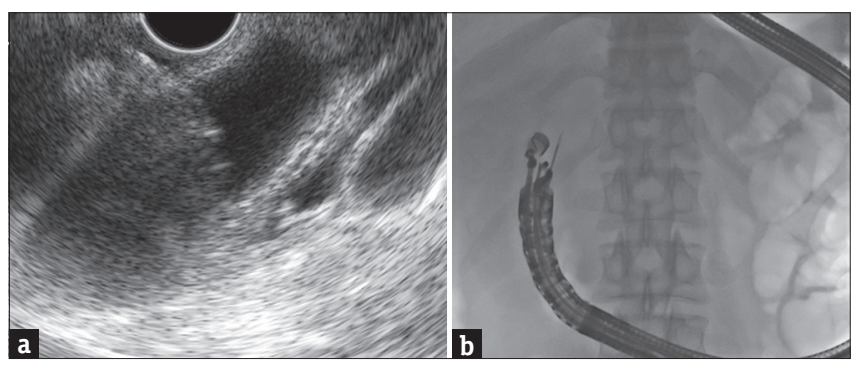

Figure 3: ( $\mathrm{a}$ and $\mathrm{b}$ ) Endoscopic ultrasound-guided puncture of dilated bile duct

Tokyo, Japan) was advanced to the hilar side of the CBD [Figure 5]. A fully covered self-expanding metallic stent (SEMS) (WallFlex; $10 \mathrm{~mm}$ diameter, $6 \mathrm{~cm}$ length, Boston Scientific, Natick, Massachusetts) was placed into the bile duct after dilatation of the transmural tract over the guidewire [Figure 6]. The patient had an uneventful postprocedure course, and the pruritus subsided within 3 days of the procedure and jaundice started decreasing. The patient was thereafter referred to oncology services for further management.

On follow-up, patient became anicteric 14 days after the procedure and is jaundice free after 2 months of follow-up. There has also been no recurrence of gastrointestinal bleed. 


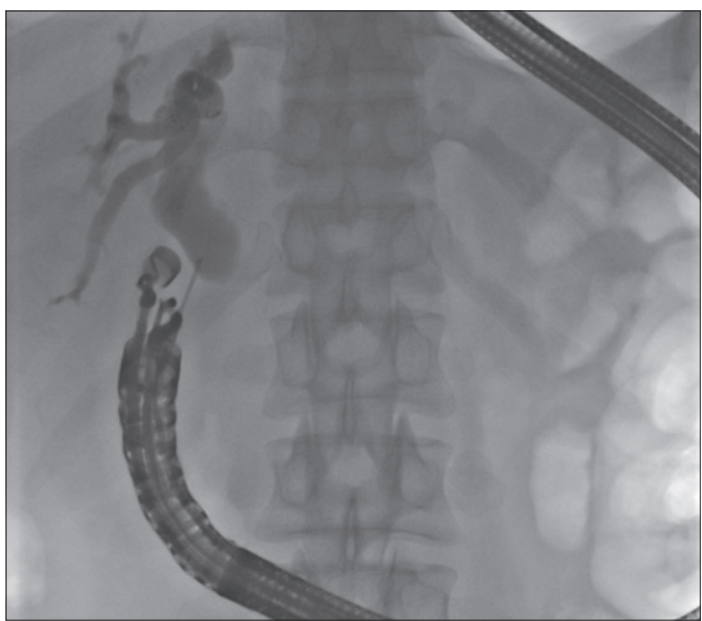

Figure 4: Endoscopic ultrasound cholangiogram: Dilated common bile duct

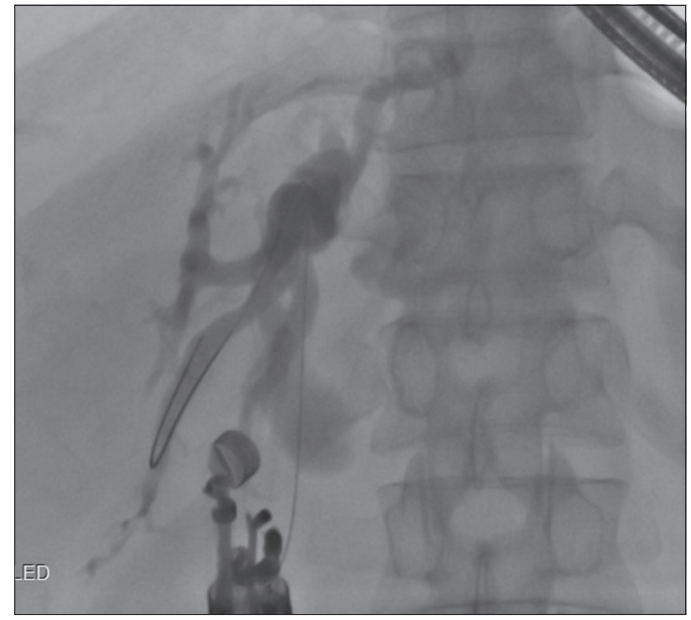

Figure 5: Guidewire negotiated toward the hilum

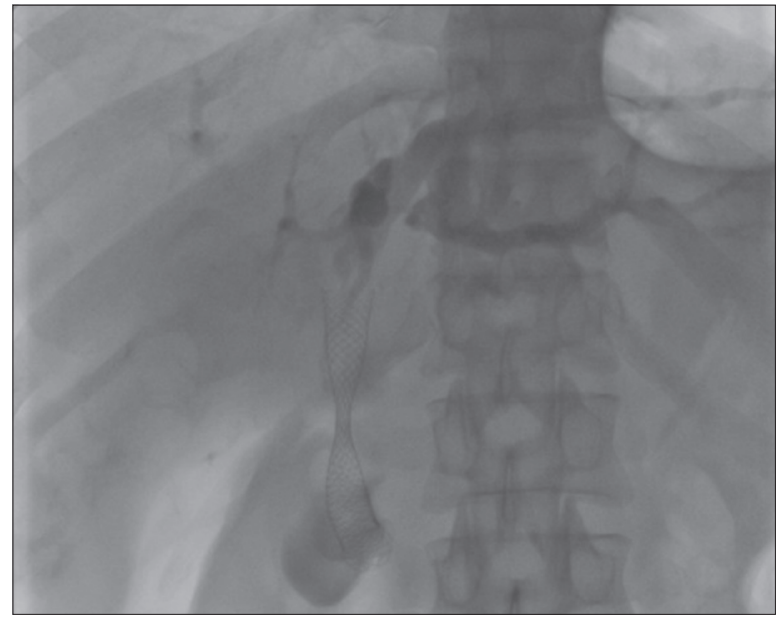

Figure 6: Fully covered self-expanding metallic stent placed

\section{Discussion}

Since 2001, when Giovannini et al..$^{[8]}$ first reported new technique of EUS-guided bilioduodenal anastomosis, there has been a gradual improvement in technique as well as accessories, and now EUS-BD is being increasingly performed in cases where ERCP is not possible. ${ }^{[1-7]}$ A systematic review of 42 studies with 1192 patients reported that the technical success rate and functional success rate of EUS BD are high $(94.71 \%$ and 91.66\%, respectively). ${ }^{[9]}$ However, it is also associated with high adverse events with frequency as high as $23.32 \%$. This increased frequency of adverse events, namely, bleeding, bile leakage, pneumoperitoneum, stent migration, cholangitis, and peritonitis limits its widespread use.

Of the various options available for EUS BD, studies have shown varying results with majority showing that both rendezvous as well as direct transluminal stenting techniques as well as both transhepatic route and transduodenal route are equally safe and effective and therefore the choice of route of access and technique used usually depends on the endoscopist's preference. ${ }^{[9-13]}$ The most concerning complication of transluminal EUS-BD is bile leakage and bleeding. Bile leakage can be theoretically prevented by the use of FCSEMS that can seal the gap between the stent and the walls of the fistula by expansion. ${ }^{[6]}$

Our case was more challenging as there was an increased risk of bleeding because of extensive bleeding duodenal infiltration. We initially used APC to coagulate the bleeding lesions and thereafter carefully chose the transmural site of puncture avoiding the involved duodenal area and finally used fully covered SEMS that would have enhanced hemostasis by tamponade effect.

\section{Conclusion}

EUS-guided choledochoduodenostomy using a fully covered SEMS is a safe and effective treatment option for relieving malignant biliary obstruction even in the presence of extensive bleeding duodenal infiltration that has been initially controlled by APC.

\section{Financial support and sponsorship}

Nil.

\section{Conflicts of interest}

There are no conflicts of interest.

\section{REFERENCES}

1. Kim YS, Gupta K, Mallery S, Li R, Kinney T, Freeman ML, et al. Endoscopic ultrasound rendezvous for bile duct access using a transduodenal approach: Cumulative experience at a single center. A case series. Endoscopy 2010;42:496-502.

2. Fabbri C, Luigiano C, Fuccio L, Polifemo AM, Ferrara F, Ghersi $\mathrm{S}$, et al. EUS-guided biliary drainage with placement of a new partially covered biliary stent for palliation of malignant biliary obstruction: A case series. Endoscopy 2011;43:438-41. 
3. Komaki T, Kitano M, Sakamoto H, Kudo M. Endoscopic ultrasonography-guided biliary drainage: Evaluation of a choledochoduodenostomy technique. Pancreatology 2011;11 Suppl 2:47-51.

4. Park DH, Jang JW, Lee SS, Seo DW, Lee SK, Kim MH, et al. EUS-guided biliary drainage with transluminal stenting after failed ERCP: Predictors of adverse events and long-term results. Gastrointest Endosc 2011;74:1276-84.

5. Kanno Y, Ito K, Koshita S, Ogawa T, Masu K, Masaki Y, et al. Efficacy of a newly developed dilator for endoscopic ultrasound-guided biliary drainage. World J Gastrointest Endosc 2017;9:304-9.

6. Kunda R, Pérez-Miranda M, Will U, Ullrich S, Brenke D, Dollhopf $\mathrm{M}$, et al. EUS-guided choledochoduodenostomy for malignant distal biliary obstruction using a lumen-apposing fully covered metal stent after failed ERCP. Surg Endosc 2016;30:5002-8.

7. Khashab MA, Messallam AA, Penas I, Nakai Y, Modayil RJ, De la Serna C, et al. International multicenter comparative trial of transluminal EUS-guided biliary drainage via hepatogastrostomy vs. choledochoduodenostomy approaches. Endosc Int Open 2016;4:E175-81.

8. Giovannini M, Moutardier V, Pesenti C, Bories E, Lelong B,
Delpero JR, et al. Endoscopic ultrasound-guided bilioduodenal anastomosis: A new technique for biliary drainage. Endoscopy 2001;33:898-900

9. Wang K, Zhu J, Xing L, Wang Y, Jin Z, Li Z, et al. Assessment of efficacy and safety of EUS-guided biliary drainage: A systematic review. Gastrointest Endosc 2016;83:1218-27.

10. Khashab MA, Valeshabad AK, Modayil R, Widmer J, Saxena P, Idrees $\mathrm{M}$, et al. EUS-guided biliary drainage by using a standardized approach for malignant biliary obstruction: Rendezvous versus direct transluminal techniques (with videos). Gastrointest Endosc 2013;78:734-41.

11. Artifon EL, Marson FP, Gaidhane M, Kahaleh M, Otoch JP. Hepaticogastrostomy or choledochoduodenostomy for distal malignant biliary obstruction after failed ERCP: Is there any difference? Gastrointest Endosc 2015;81:950-9.

12. Ogura T, Chiba Y, Masuda D, Kitano M, Sano T, Saori O, et al. Comparison of the clinical impact of endoscopic ultrasound-guided choledochoduodenostomy and hepaticogastrostomy for bile duct obstruction with duodenal obstruction. Endoscopy 2016;48:156-63.

13. Liao WC, Angsuwatcharakon $\mathrm{P}$, Isayama H, Dhir V, Devereaux B, Khor CJ, et al. International consensus recommendations for difficult biliary access. Gastrointest Endosc 2017;85:295-304. 